\title{
PRÁTICAS DE LEITURA E ESCRITA NA CULTURA DIGITAL
}

\author{
Antônia Dilamar Araújo* \\ Aline Luna Saboia ${ }^{* *}$ \\ Maria Aurea Albuquerque Sousa**
}

RESUMO: Este estudo investiga práticas de leitura e escrita, no âmbito da cultura digital, realizadas por alunos de uma escola pública no Pará. A pesquisa surgiu em um contexto em que se coíbe o uso dos smartphones na escola. Para esta pesquisa - exploratória e qualitativa - foi aplicado, nas turmas de $9^{\circ}$ ano, um questionário de questões fechadas e semiabertas. Partimos do pressuposto de que se faz necessário refletir sobre possibilidades de ação, relacionando as práticas didático-pedagógicas às práticas sociais e discursivas no meio digital em que os discentes estão imersos. Verificamos a incidência de diferentes práticas discursivas próprias da cultura digital, leitura de gêneros emergentes e a ubiquidade, porém autoria restrita. Concluímos que são necessárias ações formadoras com os professores para que possam ressignificar suas ações e ampliar o nível de criticidade dos alunos quando leem e escrevem no ambiente digital, integrando tais práticas no processo de ensino e aprendizagem.

PALAVRAS-CHAVE: Cultura digital; Escrita; Leitura.

\section{Introdução}

No Brasil, municípios e estados ${ }^{3}$ implementaram leis que proíbem o uso de smartphones no espaço escolar, conforme mostra levantamento feito por Rodrigues, Segundo e Ribeiro (2018). É possível identificar várias instituições que coíbem o uso destes

\footnotetext{
* Professora Titular da Universidade Estadual do Ceará (Uece). Doutora em Letras pela Universidade Federal de Santa Catarina (Ufsc). Realizou estágio de Pós-doutoramento na Universidade da Califórnia, Santa Bárbara (UCSB). Vice-coordenadora do grupo de pesquisa Leitura e escrita: do verbal ao Visual (Lev), cadastrado no diretório do CNPq.

${ }^{* *}$ Mestranda em Linguística Aplicada pela Universidade Estadual do Ceará (Uece). Participa do grupo de estudos e pesquisa Linguagem, Formação e Trabalho (Lift) da Uece.

${ }^{* * *}$ Mestre e Doutoranda em Linguística Aplicada pela Universidade Estadual do Ceará (Uece).

${ }^{3}$ Conforme Rodrigues, Segundo e Ribeiro (2018): Minas Gerais, São Paulo, Amazonas, Rio Grande do Sul, Santa Catarina, Rio de Janeiro, Distrito Federal, Pernambuco, Paraná, Ceará.
} 
dispositivos durante o período em que os alunos se encontram na escola. Essa realidade também ocorre em outros países, como a França, cujo decreto-lei vigora desde 2018. Em todos os casos, entre os problemas alegados estão: a distração que os celulares causam nos alunos, cyberbullying e acesso a conteúdos perigosos para os jovens.

Em contrapartida, encontramos pesquisadores e professores (LUZ, 2017; LUCENA, 2016; MOURA, 2010), no contexto nacional e estrangeiro, que buscam compreender a complexidade das práticas socias e discursivas em que os jovens da geração contemporânea estão inseridos. Os trabalhos destes autores discutem ações interventivas e experiências de cunho pedagógico, desenvolvem discussões teóricas e sugestões metodológicas que sinalizam ser pedagogicamente produtivo integrar as mídias móveis (smartphones e tablets) ao contexto de ensino e aprendizagem dentro da sala de aula.

Do nosso ponto de vista, alinhadas com Buzato (2006), acreditamos que antes de fetichizar, defender ou combater as tecnologias é mais importante e produtivo buscar compreender como elas se incorporam nas nossas práticas sociais e na cultura como um todo. Como parte de uma cultura, o uso de uma tecnologia não se desvincula das práticas discursivas ou da linguagem que utilizamos. Como sabemos, é papel da escola entender e ensinar sobre os usos e funcionamento da língua, o que não se restringe ao ensino do cânone a língua escrita e escolarizada. Também é papel da escola promover o pensamento crítico, preparar o aluno para ser um leitor e produtor de textos com sua própria marca de autoria. E este espaço de produção parece ser propício também em ambiente digital, utilizando o smartphone como a principal ferramenta, uma vez que muitos alunos dispõem desta.

É preciso destacar ainda que os usos de tecnologias e de práticas de letramento se diferem não somente pela região geográfica, mas também (e principalmente) pelo contexto cultural e socioeconômico no qual estamos inseridos (STREET, 2014). Tais diferenças determinam quais as práticas de leitura e escrita que cada grupo social realiza no meio digital. Assim, esta pesquisa responde a uma problemática identificada no contexto amazônico, entre jovens de uma escola pública de ensino fundamental, com características 
peculiares e especificidades que os diferem de contextos da região sul e sudeste do país, por exemplo.

Com base na discussão exposta, esta pesquisa tem como objetivos identificar e analisar as práticas de leitura e escrita desenvolvidas por alunos quando acessam o ambiente digital utilizando o smartphone. No contexto da escola lócus desta pesquisa, estes dispositivos foram proibidos, mas continuam sendo confiscados pelos professores durantes as aulas. Muitas vezes, a direção recorre a punições e suspensões que se mostram ineficientes. Diante disso, propomos realizar, inicialmente, uma pesquisa exploratória em que pudéssemos responder à questão: Quais são as práticas de leitura e escrita que os alunos do nono ano do Ensino Fundamental realizam quando acessam o espaço digital por meio dos smartphones? Ao identificar estas práticas poderemos, numa fase subsequente do projeto que empreendemos na escola, propor ações de discussão, reflexão e intervenção de acordo com os questionamentos e problemas que foram levantados naquele contexto em particular.

\section{Ler e escrever na cultura digital}

Martins (2018) explica que a definição central da palavra cultura está voltada para as práticas sociais humanas e sua diversidade. O mundo globalizado permitiu que todas essas culturas se tornassem conhecidas e, mais, que interagissem e incorporassem características umas das outras. Com o avanço da tecnologia, essas práticas humanas passaram a apresentar-se também no meio virtual. Isto posto, reiteramos que, neste trabalho, utilizamos o conceito de "cultura digital" desenvolvido por esse autor, que a define como "um conjunto de práticas sociais que acontecem de forma singular no espaço social digital" (MARTINS, 2018, p. 54, grifo do autor). Essa singularidade diz respeito à “capacidade de manipulação simbólica automática”, característica que diferencia o digital “de todos os outros suportes de manipulação que já foram antes desenvolvidos pelo ser humano”, esclarece Martins (2018, p. 55).

O autor também argumenta que essa característica singular é a chave para refletir sobre as práticas sociais que emergem e se estabilizam no mundo online. Com isso, ele nos 
apresenta quatro conjuntos de práticas sociais existentes: práticas informacionais (cultura do hiperlink), práticas comunicacionais (cultura da mensagem instantânea), práticas relacionais (cultura da timeline) e práticas curatoriais (cultura do algoritmo). Todas essas práticas fazem parte da realidade interativa virtual.

A internet nos trouxe uma nova forma de acesso às informações, os hiperlinks. Através deles, podemos acessar conteúdos diferentes e criar nossa própria rede de informação. Ao assistir um jornal televisivo, por exemplo, temos acesso apenas ao que o jornalista apresenta naquele canal, caso queiramos outro tipo de informação, é necessário mudar de emissora. A Web, no entanto, nos permite acessar vários canais, saltar, voltar, descartar informações, aprofundar temas de interesse pessoal etc. Ademais, também podemos ser produtores, criando novos hipertextos, remixando, estabelecendo novas conexões com textos, imagens, tabelas etc. Com isso,

a produção do hipertexto torna-se regra, modo de escrita, hábito socializado e incorporado em estratégias de escrita, formas de arte, vendas de produto e componente ativo de cursos de formação que ensinam as "boas práticas" da socialização na web. (MARTINS, 2018, p. 56, grifos do autor)

$\mathrm{O}$ avanço da internet e das mídias digitais ampliou ainda mais as formas de comunicação. Inicialmente, meios assíncronos, como o e-mail, eram uma grande inovação. Hoje, porém, a sociedade está imersa em uma cultura de mensagens instantâneas, fruto das novas práticas comunicacionais. Assim, nunca dantes fora tão fácil manter contato com o outro, um contato rápido e multimodal ${ }^{4}$ (fotos, áudios, vídeos, emojis, texto escrito...) estabelecido pelos novos dispositivos móveis, especialmente o smartphone e seus aplicativos. Estes, por sua vez,

\footnotetext{
${ }^{4}$ Multimodalidade "envolve um complexo jogo entre textos escritos, cores, imagens, elementos gráficos e sonoros, enquadramento, perspectiva da imagem, espaços entre imagem e texto verbal, escolhas lexicais, com predominância de um ou de outro modo, de acordo com a finalidade da comunicação, sendo, portanto, recursos semióticos importantes na construção de diferentes discursos" (SANTOS, 2011, p. 3).
} 
modificam não apenas a intensidade e a temporalidade da interação, mas também sua qualidade, gerando novas dinâmicas de conversação, em que tipos novos de mensagens são produzidos, novas formas de utilização do texto e escrita. (MARTINS, 2018, p. 57)

Essa interação através de textos multimodais amplia a conexão entre as pessoas, que passam a valorizar essas relações virtuais criadas a partir de suas timelines. "Expressões como 'curtir' passam a ganhar novas dimensões sociais e efeitos simbólicos que parecem induzir modos específicos de relacionamento social" (MARTINS, 2018, p. 58, grifo do autor). As atualizações constantes de mensagens, de curtidas, de seguidores, de trending topics ${ }^{5}$ etc. criam dependência nas pessoas; essas são as práticas relacionais da modernidade tardia na qual vivemos.

As práticas curatoriais podem ser percebidas com uma simples busca no Google. Após isso, aparecerão, insistentemente, na sua caixa de e-mail e/ou nas páginas de navegação do seu computador ofertas e propagandas do que foi buscado. A chamada web semântica parece ler nossa mente, mas, na verdade, lê algoritmos. Isso ocorre também nas redes sociais, os algoritmos selecionam o conteúdo a ser visto, sempre repetindo aquilo que você mais acessa, mais curte, mais comenta etc. Uma consequência dessa "manipulação digital" é a redução do seu horizonte de leituras, de interações, de contato com o diferente, com o desconhecido, com a "totalidade dos conteúdos disponíveis para visualização" (MARTINS, 2018, p. 58).

A conectividade e a multimodalidade textual também influenciam na construção do sujeito leitor. Santaella (2014) afirma haver quatro tipos de leitores, que surgiram conforme a evolução social e que, atualmente, podem coexistir e complementar-se, são eles: o leitor contemplativo, o leitor movente, o leitor imersivo e o leitor ubíquo. O primeiro está relacionado ao período pré-industrial, à leitura impressa e às imagens fixas, em especial telas

${ }^{5}$ A expressão trending topics surgiu a partir da rede social Twitter e corresponde aos assuntos mais comentados na Internet. 
de pintura. É um leitor intimista, que necessita de silêncio e recolhimento. Em sua contemplação não há pressa, “o tempo não conta” (SANTAELLA, 2014, p. 30).

Já o leitor movente surge juntamente com a sociedade moderna, impulsionada pelo capitalismo e pela expansão demográfica. A leitura se torna acelerada e híbrida: jornais, fotografias, cartazes publicitários... tudo novo a cada dia, novas informações, novas formas, novas cores. A autora evidencia que

esse leitor aprendeu a transitar entre linguagens, passando da imagem ao verbo, do som para a imagem com familiaridade imperceptível. Isso se acentua com o advento da televisão [...]. Assim, enquanto a cultura do livro tende a desenvolver o pensamento lógico, analítico e sequencial, a exposição constante a conteúdos audiovisuais conduz ao pensamento associativo, intuitivo e sintético. (SANTAELLA, 2014, p. 31)

O terceiro leitor segue as características do leitor movente, porém de forma mais intensa. A sociedade da hipermídia fez surgir um leitor imersivo, com acesso ainda mais amplo a todo tipo de informação, capaz de criar, modificar e relacionar textos intersemióticos. "Cognitivamente em estado de prontidão, esse leitor conecta-se entre nós e nexos, seguindo roteiros multilineares, multissequenciais e labirínticos que ele próprio ajuda a construir" (SANTAELLA, 2014, p. 31).

Por último, o leitor ubíquo, o mais novo leitor, fruto das redes sociais digitais e da evolução dos dispositivos móveis. Para esse leitor contemporâneo onipresente,

acessar e enviar informações, transitar entre elas, conectar-se com as pessoas, coordenar ações grupais e sociais em tempo real tornou-se corriqueiro. Assim, o ciberespaço digital fundiu-se de modo indissolúvel com o espaço físico. Uma vez que as sobreposições, cruzamentos, intersecções entre eles são inextricáveis[...]. (SANTAELLA, 2014, p. 34)

A autora também esclarece que o perfil cognitivo do leitor ubíquo tem como característica uma atenção parcial contínua. Devido aos diferentes focos, as respostas são imediatas, porém pouco reflexivas. A comunicação móvel multimodal e multimidiática é, 
desse modo, incompatível com o perfil do primeiro leitor, que pondera, elucubra e se apropria do conhecimento, daquilo que desfruta, da informação que lhe é oferecida.

Nessa perspectiva, cabe falarmos de letramento que correlaciona a leitura e a escrita às práticas socio-discursivas, ou, de forma mais específica, baseia-se em desenvolver

habilidades que possibilitam ler e escrever de forma adequada e eficiente, nas diversas situações pessoais, sociais e escolares em que precisamos ou queremos ler ou escrever diferentes gêneros e tipos de textos, em diferentes suportes, para diferentes objetivos, em interação com diferentes interlocutores, para diferentes funções. (SOARES, 2014, n.p.)

Repaldadas por Soares, Kleiman, Rojo e outros insignes autoras e autores da área, acreditamos que a escola é uma importante agência de letramento e que uma de suas atribuições é formar alunos capazes de realizar leituras crítico-interpretativas e produzir textos partindo de reflexões e transformações do conhecimento. Essa formação toma uma importância ainda maior diante da realidade leitora dessa nova geração de alunos, em sua maioria leitores ubíquos.

A crescente convergência da mídia atual significa que precisamos abordar as habilidades e competências - os múltiplos letramentos demandadas pelo conjunto de formas contemporâneas de comunicação. Em vez de só acrescentar o letramento midiático ou digital ao menu curricular, ou colocar TIC noutra matéria escolar. (BUCKINGHAM, 2010, p. 53)

Logo, concordamos com Buckingham quando ele diz que a escola não "pode darse ao luxo de ignorar o papel cada vez mais significativo que a mídia digital passou a desempenhar na vida da maioria dos jovens” (BUCKINGHAM, 2010, p.53). Segundo o autor, crianças e jovens do mundo atual têm uma vida permeada pela mídia moderna, especialmente fora da escola. Ocorre que, na maioria das vezes, a escola implementa a tecnologia, porém em níveis básicos (softwares de escrita, acesso a sites específicos, exercícios tradicionais com estruturas "divertidas" aplicados em computadores/tablets etc.), 
fato que gera desinteresse nos alunos, os quais no seu dia a dia mantêm contato com mídias digitais avançadas, além da autonomia de escolha e de aprendizado oferecida pelas mídias.

Os estudantes seguem sua intuição e a lógica dos programas, sites e aplicativos e, por meio de erros e acertos, conseguem manusear as ferramentas e ampliar o domínio das mídias digitais. Por conseguinte, explica Buckingham (2010), o aprendizado ocorre por meio da exploração, da experimentação, do aprender fazendo. Todavia, isso não é suficiente se lhes falta criticidade no uso, por isso a relevância da relação entre professores e alunos. O professor é um agente importante na formação crítico-reflexiva dos discentes, explorar os discursos, as intenções de produção e as ideologias por trás dos textos que circulam no meio digital é indispensável.

Acerca do trabalho docente, o autor supracitado aponta que os estudos costumam voltar-se para o desinteresse e a falta de preparo dos professores ou para a necessidade de a escola tornar-se tecnológica, porém o autor defende que o foco deveria estar em entender "como professores e alunos poderiam querer usar a tecnologia e sobre o que precisamos saber acerca dela" (BUCKINGHAM, 2010, p. 42). O entusiasmo no uso das mídias é a chave para um desempenho mais produtivo dos alunos nas atividades escolares e um maior domínio das tecnologias modernas pelos professores.

Podemos afirmar, de modo geral, que redes sociais e outros aplicativos com funções múltiplas e multimodais são de uso diário na vida pessoal de todos nós. Desse modo, esse aspecto poderia ser um ponto comum de interesse entre docentes e discentes. No tocante aos estudos linguísticos, professores de Português, por exemplo, podem recorrer aos diferentes gêneros existentes na web para serem explorados em sala de aula, como os memes, pertencentes às práticas sociais da cultura digital do nosso tempo expostas por Martins (2018).

Araújo (2016) esclarece que os gêneros oriundos do meio digital são reelaborações dos gêneros discursivos já existentes e que tais reelaborações podem ser criadoras ou inovadoras. As primeiras, dão origem a gêneros diferentes, já as segundas, modificam características de um gênero sem transformá-lo em um novo, explica o autor. "As 
reelaborações criadoras se mostram um processo mais complexo, posto que origina gêneros mais inclinados à emergência (com maior grau de ineditismo ou novidade) ou à estandardização (mais próximos de gêneros já existentes)" (COSTA; ARAÚJO, 2011 apud ARAÚJO, 2016, p. 57).

Logo, memes e outros tipos de remix podem ser classificados como gêneros emergentes, enquanto um vídeo caseiro de alguém cantando, por exemplo, se classifica como gênero estandardizado, pois é uma reelaboração criadora que se aproxima de um gênero já existente, o videoclipe. Essas constantes reelaborações estão presentes no cotidiano da maioria dos jovens, direcionando suas práticas nos meios digitais e, consequentemente, influenciando nas suas formações leitora, escrita e crítica.

\section{Contexto da pesquisa}

Os sujeitos desta pesquisa foram alunos do $9^{\circ}$ ano do Ensino Fundamental de uma escola pública, localizada em um município do sudeste do Estado do Pará. A escola oferece as séries finais do ensino fundamental $\left(6^{\circ}\right.$ ao $9^{\circ}$ ano) e no ano letivo de 2018 atendeu aproximadamente 700 alunos nos dois turnos. Embora a escola funcione na área central da cidade, a maioria dos alunos reside em regiões mais distantes, de maior vulnerabilidade social, e dependem do transporte escolar público para ir às aulas, conforme nos relatou a diretora.

Neste contexto, surgiram frequentes queixas dos professores sobre o uso do celular em sala de aula como um problema com o qual não sabiam lidar, especialmente nas turmas do $9^{\circ}$ ano. Assim, tal demanda foi a motivação inicial para a realização dessa pesquisa. Inicialmente foi realizada uma conversa informal com os alunos do $9^{\circ}$ ano sobre os usos das mídias digitais em seu cotidiano. Nas respostas prévias, muitos alunos revelaram possuir mais de uma rede social e acessá-las diariamente, além de realizar outras atividades,

\footnotetext{
6 "O remix se caracteriza por sua vinculação a uma fonte primeira, que passa a ser retomada pelo sujeito de diferentes formas, gerando releituras criativas dessa matriz, que inspiram novas construções de sentido” (NAVAS, 2010 apud ARAÚJO, 2016, p. 58).
} 
por exemplo assistir a vídeos. A partir dessa conversa, verificamos a importância de uma pesquisa exploratória a fim de identificar que tipos de práticas da cultura digital esses alunos dominam e como elas podem ser direcionadas para uma ação didático-pedagógica de formação leitora e produção escrita a ser executada pelos professores em uma subsequente ação interventiva.

\section{Natureza da pesquisa, instrumento de coleta e corpus}

Trata-se de uma pesquisa exploratória, de natureza aplicada, com abordagem qualitativa, uma vez que buscamos uma maior proximidade com o objeto de estudo de forma que compreendêssemos as circunstâncias de uso da língua no meio digital por esses estudantes e conseguíssemos auxiliar os professores a lidar com as vicissitudes do seu trabalho na escola em questão.

O instrumento de coleta do corpus foi um questionário com 25 questões semiabertas que solicitavam informações sobre: idade, sexo, tipos de dispositivos digitais utilizados, uso de redes sociais e outros aplicativos, tempo de acesso à internet e práticas de leitura e escrita nos ambientes digitais. Os questionários foram aplicados a 132 alunos, somativo das turmas do $9^{\circ}$ ano, em outubro de 2018, durante as aulas de Língua Portuguesa e Língua Inglesa, perante o consentimento dos respectivos professores.

O corpus analisado corresponde a $40 \%$ do total coletado, o equivalente a 50 questionários. Tomamos como critério de seleção o fato de não haver respostas em branco, uma vez que foram identificados muitos questionários incompletos. Acreditamos que isso tenha ocorrido por razões de dúvidas sobre determinadas questões ou tempo insuficiente para respondê-las.

\section{Análise dos dados}

Primeiramente, procuramos identificar a idade e o sexo do(a) estudante. Verificamos que 35 são do sexo feminino e 15 são do sexo masculino, com faixa etária 
variando entre 14 a 18 anos. Porém, a predominância de idade foi de alunos com idade entre 14 e 15 anos.

A pergunta inicial do questionário era acerca dos tipos de dispositivos pelos quais o(a) jovem tinha acesso à internet. Segundo os dados, 45 alunos usam o smartphone, 04 alunos dispõe do computador de casa e 01 aluno acessa em lanhouses. Entre os que afirmaram utilizar smartphone, 03 indicaram que também acessam pelo computador de casa. Nenhum deles selecionou a opção 'computador da escola'.

Gráfico 1 - Dispositivos de acesso à internet

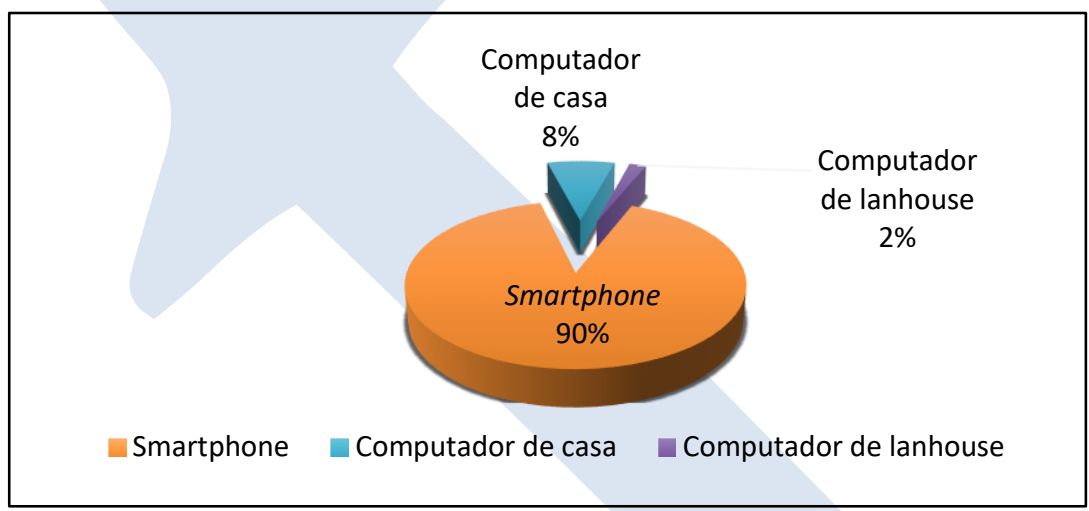

Fonte: Elaboração própria.

Merije (2012) afirma que o uso dos celulares prevalece em razão de estes dispositivos serem multifuncionais e menos custosos que um computador pessoal. Conforme o autor, para muitos jovens o smartphone é o primeiro computador, pela convergência de suas funcionalidades, pelo preço e, principalmente, pela mobilidade. De fato, nesse contexto estudado, a maioria não possui computador em casa e realiza grande parte das atividades de acesso a redes, pesquisas escolares e interações diversas por meio do celular. 
A segunda questão procurou identificar em qual tipo de rede o acesso à internet era mais frequente. A conexão em domicílio através de banda larga foi apontada por 36 alunos, dos quais 05 indicaram acessar também por meio das redes móveis. Dez usam apenas as redes móveis, 04 apenas têm acesso na escola e 01 revelou ter acesso apenas em casa de amigos. Durante o período desta pesquisa foi constatado que a administração escolar não permite que os alunos tenham acesso à conexão. $\mathrm{O}$ acesso é liberado apenas em alguns dias da semana após o término do período de aula, mas poucos alunos indicaram utilizar este meio.

Sobre o uso de redes sociais e demais softwares, todos os alunos afirmaram assistir vídeos no Youtube e usar o aplicativo de mensagens Whats $A p p$, 35 estudantes possuem perfil no Facebook, 15 também possuem perfil no Instagram, 20 alunos usam o celular para assistir filmes no serviço de streaming Netflix, 10 participam de jogos online e apenas 01 aluno possui perfil no Twitter.

Quando questionados sobre o uso de e-mail, muitos responderam que haviam criado uma conta de e-mail como parte de uma atividade solicitada pela professora de português, fato que chamou nossa atenção. Em conversa posterior com a professora, esta disse que os alunos deveriam criar um e-mail, enviar uma mensagem para ela contando um segredo e uma mensagem para um colega da classe, o qual deveria responder. A professora afirmou que julgava importante que os alunos conhecessem a ferramenta, pois nenhum deles a utilizava, apesar de ser uma ferramenta útil em muitas situações, segundo ela.

Supomos, contudo, que os alunos não fazem uso do e-mail como troca de mensagens em sua função social comumente empregada, porém sabe-se que em algum momento eles precisaram utilizá-lo devido ao acesso às redes sociais das quais participam, considerando que ter um endereço de e-mail é pré-requisito para criar um nome de usuário e conectar-se em qualquer software e aplicativo.

Os resultados revelam o uso massivo dos aplicativos de mensagens instantâneas e das redes sociais, práticas comunicacionais da cultura digital, conforme a classificação de Martins (2018). Estas apareceram como as principais formas de interação social desses 
alunos. As respostas mais frequentes à pergunta sobre o que fazem ao navegar na rede foram: assistir vídeos no Youtube, baixar e ouvir músicas, entrar no Facebook, entrar no Instagram, entrar no Whats App e ver filme na Netflix. A opção participar de jogos online foi marcada apenas em cinco respostas. Esses resultados indicam que, nesse contexto de pesquisa, o uso do smartphone se dá, principalmente, para o entretenimento, interação e comunicação.

$\mathrm{Na}$ questão sobre o que mais gostam de ler na internet, $30 \%$ das respostas indicam conteúdos religiosos como uma leitura frequente, certamente pelo fato de muitos alunos pertencerem a grupos evangélicos atuantes na comunidade local. Verificamos ainda que se sobressaem os gêneros emergentes multimodais (ARAUJO, 2016), como mangás e tirinhas, sendo, todavia, a opção "memes e imagens engraçadas" indicada pelo grupo como a leitura preferida. A leitura de notícias, embora não tenhamos questionado a especificação dos temas lidos neste gênero, mostrou-se como de grande interesse, seguida da leitura de conteúdos da escola. A opção 'fofocas de artistas e famosos' foi a de menor índice. Esses dados foram resumidos a seguir, vejamos:

Gráfico 2 - Leituras preferidas na internet indicadas pelos sujeitos da pesquisa

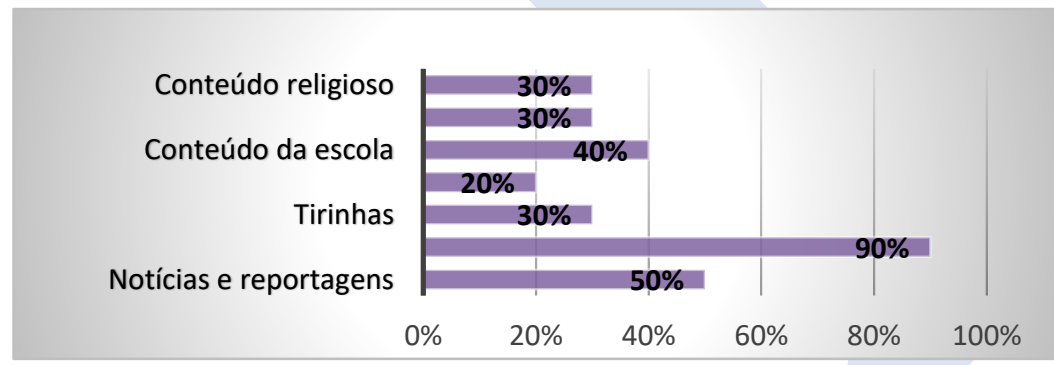

Fonte: Elaboração própria

Em relação às práticas de escrita, 90\% dos participantes responderam que escrevem no Facebook. Dentre as respostas mais recorrentes estão: "faço comentários em fotos ou no status de amigos", "posto algo que me define", "publico mensagens reflexivas" e "posto 
pensamentos do dia”. Nas questões sobre produção de vídeos, memes e outros gêneros que circulam no meio digital, apenas dois participantes revelaram que criam vídeos utilizando o smartphone, um revelou fazer vídeos "cantando e dançando" para postar na internet. Outro afirmou que posta vídeos sobre os desenhos que ele faz. Quatro participantes responderam que produzem memes com o objetivo de "fazer piada com os amigos". Nenhum dos participantes realiza atividades de escrita na internet com objetivos orientados por professores.

Quando questionados se consideram o smartphone útil para a própria aprendizagem, todos os 50 alunos afirmaram que sim. As justificativas mais frequentes foram: "nas pesquisas escolares", “esclarecer dúvidas”, “aprender mais”, “ver videoaulas”, "pesquisar o que eu não sei”, "levar a qualquer lugar", "saber das coisas que acontecem”, entre outras.. Assim, da perspectiva destes alunos, o smartphone é utilizado como uma ferramenta de apoio à aprendizagem, a qual recorrem constantemente.

\section{Discussão dos dados}

O entusiasmo dos alunos ao falarem sobre o que fazem no meio digital foi evidente durante a conversa inicial antes de aplicarmos o questionário e explicar às turmas os objetivos da pesquisa, isso nos mostra o desejo que eles têm em compartilhar e discutir suas experiências de leitura, escrita e interação no meio midiático. Tendo em vista que o fenômeno da cultura digital está intrínseco às relações sociais e aos novos modos de leitura e produção de textos, é possível compreender o micro contexto que investigamos, reflexo da aldeia global ${ }^{7}$ em rede.

Conforme os dados analisados, o crescente uso de smartphone foi verificado entre esses sujeitos, embora estejam numa região do país com dificuldades de infraestrutura e de acesso às tecnologias de comunicação. Ainda que a principal forma de acesso a conteúdos

\footnotetext{
7 “Aldeia global” é um conceito desenvolvido pelo teórico canadense Marshall McLuhan na década de 70. Para o autor, com o advento das tecnologias de informação e comunicação, as distâncias físicas e culturais se eliminaram de modo que o mundo se tornou uma grande aldeia interligada.
} 
da escola ocorra por meio deste dispositivo, há poucas ações educativas que discutam ou aproveitem a motivação presente no seu uso. Acreditamos que o smartphone pode auxiliar na aprendizagem e no letramento digital dos alunos.

Como os outros cidadãos do mundo, graças à internet esses estudantes participam das práticas da cultura digital relatadas por Martins (2018). As práticas relacionais revelamse quando eles afirmam fazer comentários em fotos e curtir páginas de seu interesse. Já as práticas comunicacionais são observadas quando eles interagem com diferentes grupos dentro do espaço das mídias sociais. Os alunos também revelaram-se leitores ubíquos, aqueles que recorrem ao celular para grande parte das práticas de linguagem escrita, verbal e imagética. Um leitor inserido na era da mobilidade que "ao carregar consigo um dispositivo móvel, a mobilidade se torna dupla: mobilidade informacional e mobilidade física do usuário" (SANTAELLA, 2013, p.21).

Esses leitores/produtores estão acostumados a textos construídos com diferentes semioses e parecem preferir ler e produzir textos multimodais, tais como vídeos do Youtube, memes, gifs, entre outros gêneros que circulam no mundo online. Para as práticas de leitura identificadas, eles usam estratégias que se adequam a este espaço: leitura rápida, móvel e sem tempo para analisar, questionar ou desconfiar do que leem. O leitor que se mostrou nesta pesquisa "é aquele que brotou nos novos espaços das redes computadorizadas de informação e comunicação" (SANTAELLA, 2013, p.20). Suas leituras também são orientadas pela própria facilidade da informação, presente na ponta dos dedos.

Consoante aos dados que analisamos, não há produção escrita substancial além dos citados comentários nas redes sociais e das mensagens instantâneas. São eventos de escrita com fins funcionais que atendem a uma finalidade imediata de comunicação ou interação. A produção de conteúdo que demanda uma escrita mais densa e de autoria, como as que se realizam em blogs e plataformas wikis, por exemplo, não apareceram neste contexto.

Sobre a escassa produção de conteúdo, não creditamos esta lacuna ao domínio das ferramentas, levando em conta que para usuários da rede mundial de informações, quando ocorre a curiosidade ou a necessidade, é fácil fazer uma busca no Google por tutoriais que 
orientam na utilização de aplicativos e outras ferramentas. O engajamento na produção de conteúdos pode se materializar a partir de um projeto bem definido, seja por interesse e motivação do usuário, ou por fazer parte de uma atividade pedagógica previamente orientada e com objetivos claros para que os alunos participem conscientes de que se trata de uma atividade autêntica de uso da linguagem, não apenas entretenimento.

A atitude da professora de português, em solicitar a criação de um e-mail e o envio de mensagens por essa plataforma, é um exemplo de atividade didático-pedagógica executável voltada para as práticas sociais e discursivas. Essa é a formação esperada para que esses alunos saiam do nível de dizer o conhecimento para o de transformar o conhecimento a partir de práticas existentes e relevantes na sociedade, que não só reproduzam informações, mas reflitam e formulem suas próprias conclusões e sejam capazes de explicitá-las de forma coesa e coerente.

Dessa forma, destacamos o papel mediador da escola e dos professores para que estes alunos não sejam apenas consumidores dos textos que circulam no meio digital. Pois, nas diferentes práticas da cultura digital em que estão imersos, é importante que se tornem também autores críticos e participativos; de acordo com o que defende Dias (2016, p.27): "a possibilidade da autoria como produção própria de conhecimento; a oportunidade de acesso à informação e de elaboração autoral dos conteúdos acessados como forma de participação e protagonismo; a autoria como inclusão digital”.

No entanto, cabe à escola enfrentar tal desafio. Por meio de formação e diálogo com os professores é possível desenvolver ações para práticas de leitura e escrita feitas com e pelos alunos no âmbito da denominada cultura digital da qual, cada vez mais, eles fazem parte. Nesse contexto, o que parece mais laborioso para os professores é tornar seus alunos autênticos aprendizes, produtores de conteúdo e leitores críticos, saindo da comum passividade presente nos usuários das mídias digitais.

\section{Considerações finais}


As respostas dos estudantes analisadas mostram que eles são usuários assíduos das redes sociais e outros aplicativos. Verificamos também que eles desejam que a escola aceite e inclua o celular como ferramenta de ensino. Assim, acreditamos que é possível vincular tais mídias digitais à realidade escolar por meio de planejamento das práticas pedagógicas. Reconhecemos o desafio em implantar nas escolas esse tipo de atividade, principalmente se há algum tipo de barreira na percepção dos professores. Não obstante, vale ressaltar que vetar ou ignorar a realidade social dos estudantes cria um obstáculo na relação professoraluno, além de ampliar as dificuldades de lidar com esses jovens, uma vez que autoritarismo e ensino tradicional já não "surtem efeito" há muito tempo.

Como professores somos chamados a estabelecer vínculos mais efetivos com nossos alunos, gerando maior envolvimento nas aulas e logrando os objetivos de ensino desejados. Nesse caso, a linguagem é a ferramenta primordial da educação e a língua tem características essencialmente sociais, logo, como não inserir práticas sociais de leitura e escrita nas práticas de ensino? Ao usar o celular em sala de aula com fins pedagógicos não se está implementando apenas uma ferramenta, mas associando o ensino ao uso real da língua, por isso não devemos reduzir a tecnologia apenas a seus artefatos técnicos (ARAÚJO, 2016).

Neste trabalho, tratamos sobre o uso do celular na sala de aula devido a uma demanda dos professores da escola em que foi realizada a pesquisa. No entanto, podemos afirmar que essa demanda existe em diversas instituições de ensino. Sabemos que há divergência quanto à aceitação ou proibição desse artefato e esperamos contribuir com as discussões através das reflexões aqui expostas. Ressaltamos que o presente estudo tem como objetivo final retornar ao coletivo de professores da escola a fim de dialogar com estes acerca do corpus coletado e analisado. Ouvi-los é tão importante quanto argumentar sobre as questões teóricas aqui discutidas, uma vez que as possibilidades de mudança devem ser debatidas a partir da realidade de trabalho destes profissionais.

Em conclusão, ressaltamos que a escola é chamada a ser uma agência de letramentos múltiplos (ROJO; MOURA, 2012) e que há uma demanda para que os professores 
trabalhem com práticas de leitura e produção textual envolvendo mídias digitais. Contudo, não excluimos os materiais impressos, em realidade é possível mesclar celular, livros, redes sociais, caderno, lápis, leitura coletiva, debate, plataformas online, vídeos, memes... e tantos outros gêneros e ferramentas. Entrelaçar as culturas impressa e digital é o caminho a seguir, assim consideramos.

\section{READING AND WRITING PRACTICES IN DIGITAL CULTURE}

ABSTRACT: This study investigates reading and writing practices in the digital culture presented by students of a public school in Pará. The research emerged in a context where the use of mobile phones inside the school is not permitted. Our main assumption is the necessity to reflect upon possibilities of action, integrating the curricular activities with the discursive practices that take place in the digital environment where students are immersed. For this exploratory and qualitative research a questionnaire of closed and semi-closed questions was applied in the ninth grade of elementary school. The results have shown the incidence of different discursive practices related to digital culture, reading of emerging genres and ubiquity, but meaningful writing activities have not been found . We conclude that training actions are needed with teachers so they can redefine their approach and increase the students' capacity to think critically when they read and write in the digital environment, relating those practices to their learning process.

KEYWORDS: Digital culture; Reading; Writing.

\section{REFERÊNCIAS}

ARAÚJO, Júlio César. Reelaborações de gêneros em redes sociais. In: ARAÚJO, Júlio César; LEFFA, Vilson. Redes sociais e ensino de línguas: o que temos de aprender? São Paulo: Parábola Editorial, 2016. p. 49-63.

BUCKINGHAM, David. Cultura digital, educação midiática e o lugar da escolarização. Educação e Realidade, Porto Alegre: UFRGS, v. 35, n. 3, p. 37-58, set./dez. 2010.

BUZATO, Marcelo. Letramentos digitais e formação de professores. In: CONGRESSO IBERO-AMERICANO EDUCAREDE: Educação, Internet e Oportunidades, 3, 2006, São Paulo. Anais do III Congresso Ibero-Americano Educarede. São Paulo: Portal Educarede, 2006.

DIAS, Laryssa Amaro Naumann Pereira. Multiletramentos na sala de aula: entre a intuição e a intencionalidade. 2016. 100 f. Dissertação (Mestrado em Educação) - Departamento de Educação, Pontifícia Universidade Católica do Rio de Janeiro, Rio de Janeiro, 2016.

LUCENA, Simone. Cultura digital e tecnologias móveis em Educação. Educar em Revista, Curitiba: UFPR, n. 59, p. 277-290, jan./mar. 2016. 
LUZ, Sandra Dias da. Miradas no caleidoscópio: Oficinas de multiletramentos com dispositivos móveis na criação de narrativas digitais na educação básica. 2017. 229 p. Dissertação (Mestrado em Educação) - Centro de Ciências da Educação, Universidade Federal de Santa Catarina, Florianópolis, 2017.

MARTINS, Dalton Lopes. As práticas da cultura digital. Revista do Centro de Pesquisa e Formação, n. 7, p. 51-60, nov. 2018.

MERIJE, W. Mobimento, educação e comunicação mobile. São Paulo: Editora Peirópolis, 2012.

MOURA, Adelina Maria Carreiro. Apropriação do telemovel como ferramenta de mediação em mobile learning: estudos de caso em contexto educativo. 2010, 630 p. Tese (Doutorado em Ciências de Educação) - Instituto de Educação, Universidade do Minho, Braga, 2010.

ROJO, Roxane; MOURA, Eduardo. Multiletramentos na escola. São Paulo: Parábola, 2012.

SANTAELLA, Lucia. O leitor ubíquo e suas consequências para a educação. In: TORRES, Patrícia Lupion (Org.). Complexidade: redes e conexões na produção do conhecimento. Curitiba: SENAR - PR, 2014. p. 27-44

. Desafios da ubiquidade para a educação. Revista Ensino Superior UNICAMP/

Especial: as novas mídias e o ensino superior, 9a ed., 2013, p.19-28. Disponível em:

<https://www.revistaensinosuperior.gr.unicamp.br/edicoes/edicoes/ ed09_abril2013/NMES_1.pdf>_Acesso em: 08 dez. 2018.

SANTOS, Záira Bomfante. A concepção de texto e discurso para a semiótica social e o desdobramento de uma leitura multimodal. Revista Gatilho, Juiz de Fora: UFJF, v. 13, 2011, p. 1-13.

RODRIGUES, Francisco S.; SEGUNDO, Geny Lúcia S.; RIBEIRO, Lissiane Maria da S. O uso do celular na sala de aula e a legislação vigente no Brasil. III Congresso sobre tecnologias na Educação: Cultura Maker na Escola. Fortaleza, Ceará, 2018.

SOARES, M. Letramento. In: FRADE, Isabel Cristina A. da Silva.; VAL, Maria da Graça Costa; BREGUNCI, Maria das Graças de Castro. (Org. geral) Glossário Ceale: termos de alfabetização, leitura e escrita para educadores. Belo Horizonte: FaE-UFMG, 2014.

STREET, Brian. V. Letramentos sociais: abordagens críticas do letramento no desenvolvimento, na etnografia e na educação. Tradução de Marcos Bagno. 1.ed. São Paulo: Parabola Editorial, 2014.

Recebido em: 22/08/2019. Aprovado em: 14/10/2019. 